\title{
Online-Based Survey on College Students' Anxiety During COVID-19 Outbreak
}

\author{
This article was published in the following Dove Press journal: \\ Psychology Research and Behavior Management
}

\author{
Wantong $\mathrm{Han}^{1-3}$ \\ Lingzhong $\mathrm{Xu}^{1-3}$ \\ Aimin $\mathrm{Niu}^{4}$ \\ Yurong Jing ${ }^{1-3}$ \\ Wenzhe Qin ${ }^{1-3}$ \\ Jiao Zhang ${ }^{1-3}$ \\ Xiang Jing ${ }^{5}$ \\ Yali Wang ${ }^{6}$
}

'Centre for Health Management and Policy Research, School of Public Health, Cheeloo College of Medicine, Shandong University, Jinan, Shandong, People's Republic of China; ${ }^{2} \mathrm{NHC}$ Key Laboratory of Health Economics and Policy Research, Cheeloo College of Medicine, Shandong University, Jinan, Shandong, People's Republic of China; ${ }^{3}$ Center for Health Economics Experiment and Public Policy Research, Cheeloo College of Medicine, Shandong University, Jinan, People's Republic of China;

${ }^{4}$ Department of Public Health, Shandong Provincial Hospital Affiliated to Shandong First Medical University, Jinan, People's Republic of China; ${ }^{5}$ Yuncheng Central Hospital, Yuncheng, Shanxi, People's Republic of China; ${ }^{6}$ Henan Provincial Center for Disease Control and Prevention, Zhengzhou, Henan, People's Republic of China

Correspondence: Lingzhong Xu School of Public Health, Cheeloo College of Medicine, Shandong University, Mailbox No. I I0, 44 Wenhuaxi Road, Jinan, 2500 I2,

Shandong, People's Republic of China

Tel +86-053I-8838-2648

Fax +86-053I-88382533

Email lzxu@sdu.edu.cn

Aimin Niu

Department of Public Health, Shandong Provincial Hospital Affiliated to Shandong First Medical University, No. 324 jingwu

Road, Huaiyin District, Jinan, 25002I,

People's Republic of China

Tel +86-1866-370-2722

Fax +86-053I-8792I 022

EmailnamI106@163.com

\begin{abstract}
Purpose: Studies have suggested that public health emergencies can have many psychological effects on college students, therefore, the aim of this study is to investigate current situation of college students' anxiety and its determinants in the time of an unexpected pandemic.
\end{abstract}

Patients and Methods: We conducted convenience sampling to collect the data through network-based online questionnaires in February 2020, a total of 17,876 college students were included in the analysis. Chi-square test and multivariate logistic were used to identify the associations between the outbreak experiences and anxiety detection.

Results: This study found that detection rate of anxiety among college students was $18.2 \%$. The differences in male students, students whose self-perceived risk of infection were high, who were greatly affected by the outbreak, eager to go back to school, reluctant to leave home and stay at home enough were of statistical significance among different anxiety level $(\mathrm{OR}>1, \mathrm{P}<0.05)$. And the severe anxiety rate of students who living in cities was significantly higher $(2.337[1.468,3.721])$.

Conclusion: Although our results show that anxiety among college students was at a low level, various universities should focus on the online activities and develop appropriate epidemic management plans to prevent their feelings of worry, tension and panic.

Keywords: anxiety, college students, network-based, COVID-19

\section{Introduction}

In December 2019, a novel coronavirus named COVID-19 began to spread in Wuhan, China, and its common symptoms were fever, fatigue and dry cough. In January 2020, academician Zhong Nanshan said that there was human-to-human transmission of pneumonia caused by the novel coronavirus. With hundreds of millions of people traveling or returning home for the China New Year, widespread population movements have increased the risk of spread for the virus, and a pandemic was imminent. On January 30, 2020, the World Health Organization declared a public health emergency of international concern over the global outbreak of novel coronavirus. The novel coronavirus disease has spread to 26 countries/territories outside of China and infected 75,751 patients globally (74,675 in China) as of February 20, 2020. The epidemic brought not only the risk of death from the viral infection but also social panic to people in China and the rest of the world ${ }^{1}$ and under these circumstances where many people are dying dread and despair. ${ }^{2}$ Fear of Avian Flu or other illnesses can be considered a specific type of anxiety called health-related anxiety. ${ }^{3}$ Taylor and Asmundson describe health anxiety as a useful function for human to react to physical ailments with a certain level of concern. This normal level of anxiety often causes us to take the necessary measures to prevent and alleviate illness. ${ }^{4}$ When the anxiety is chronic, 
excessive, and significantly greater than the severity of the health-related threat, it can be disabling and cause psychological disorders. ${ }^{5}$

The high risk of anxiety disorders was noted among university and college students before the pandemic started. Studies revealed that anxiety has been diagnosed in $12-43 \%$ of college and university students. ${ }^{6-8}$ Therefore, it is important for students' psychological development to adjust and reduce their anxiety level effectively when they are in the events of stress by using reasonable coping styles. ${ }^{9}$ Early studies of the outbreak focused on the novel coronavirus gene and structure modeling, host and clinical case analysis. ${ }^{10-12}$ The China National Health Commission has released guidelines to promote psychological crisis intervention for patients, people under medical observation, medical workers, and public during the COVID-19 outbreak since Jan 6, $2020 .^{13-18}$ There have been reports on the psychological impact of the epidemic among the general public, patients, medical staff, children, and older adults. ${ }^{14,15}$ Otherwise, studies have suggested that public health emergencies can have many psychological effects on college students, such as anxiety. ${ }^{19}$ College students are prone to have anxiety due to life stage, less knowledge and experience, study and other pressures, and they generally are one of the groups with high incidence of anxiety, ${ }^{20}$ therefore, a growing body of literature has focused on examining mental health among undergraduates. ${ }^{16-18}$ For example, during the outbreak of the COVID-19 pandemic, one study indicated that $24.9 \%$ of Chinese college students were afflicted with experienced anxiety ${ }^{21}$ and another study showed that the majority of Polish university students (65\%) showed mild to severe GAD. ${ }^{22}$ Thus, there is a necessity to take various prevention and intervention measures at university campuses to cope with anxiety. Our purposes of this survey are to investigate current situation of college students' anxiety and its determinants in the time of an unexpected pandemic, enrich existing researches so that various universities can guide students to effectively and appropriately regulate their emotions.

\section{Patients and Methods}

\section{Date and Sampling}

The data were derived from the survey of college students' mental health status during the COVID-19 outbreak, which was conducted by Shandong University in
February 2020. We used convenience sampling to collect the data through the Wenjuanxing platform (https://www. Wjx.cn/app/survey.aspx), shared online link through e-mail and different social media platforms (WeChat and so on) to the college students living in mainland China during the COVID-19 epidemic. The questionnaires were anonymous and each IP address can only be filled in once to ensure the confidentiality and reliability of data. The questionnaire package consisted of three components: basic conditions of students, subjective feelings related to the epidemic situation and 20 practical situation questions in the Self-Rating Anxiety Scale (SAS). In this study, we investigated 18,294 college students, who were from 31 provinces, mainland China. Questionnaires were valid if they met the following criteria: (1) lived in mainland China, during the outbreak of COVID-19; (2) No obvious logical errors in the answers; (3) The questionnaire should be completed in 5-20 minutes. Questionnaires that did not meet these criteria were excluded. Finally, 17,876 questionnaires were included in the analysis (Questionnaire effectiveness was $97.71 \%$ ).

\section{Variables \\ Anxiety Detection}

In our study, the Self-Rating Anxiety Scale was used to detect the anxiety of college students. The Self-Rating Anxiety Scale (SAS) was designed by William WK Zung in 1971 to quantify people's level of anxiety. ${ }^{23}$ The SAS scale is a 20 -item self-reported assessment device. When answering each item, the person indicates the degree to which each statement applies. Each question is scored on a Likert-type scale of 1 to 4 (based on the following replies: "a little of the time," "some of the time," "a good part of the time," and "most of the time"). The total score is obtained by summing the assessment of the 20 items. The total score multiplied by 1.25 gives the standard score. A standard cutoff score of 50 is usually used to diagnose anxiety. ${ }^{24}$ According to the China Mental Health Center, the standard score ranges are 25-49 (normal range), 50-59 (mild anxiety), 60-69 (moderate anxiety), and $\geq 70$ (severe anxiety). ${ }^{23}$ The validity and reliability of the instrument has been found to be adequate among Chinese participants, ${ }^{25}$ such as Ye et al studied the application of three anxiety rating scales in general hospitals' outpatients, and the results showed that the Cronbach's alpha of SAS scale was $0.832 .{ }^{26}$ Tian et al evaluated the reliability and validity of self-rating anxiety scale and self-rating depression scale in patients with liver 
cirrhosis, and the results showed that the Cronbach's alpha of SAS scale was $0.777 .{ }^{27}$ In this study, the Cronbach's $\alpha$ for the SAS was 0.842 .

\section{Other Variables}

Data on demographic characteristics and the subjective feelings related to the outbreak were included in this study as follows: gender (male, female), nationality (han, minority), education (two- and three-year students, undergraduate students, master and above students), character (partial outgoing, partial introverted, both, not clear), profession (medical, science and technology, liberal Arts, management class and other majors), residence (urban, town, rural), satisfaction with local epidemic control measures (high, moderate, low), concern about the outbreak (high, moderate, low), self-perceived risk of infection (high, moderate, low), impact of the outbreak (high, moderate, low), eager to back to school (Do you have any urgent desire to go back to school? Response: Yes/No/Not clear) and feelings at home (stay enough, reluctant to leave, other thoughts).

\section{Statistical Analysis}

The Data were analyzed with SPSS version 22.0 statistical software. Continuous data were presented as the mean \pm standard deviation. Chi-square test (two-tailed) was used to preliminarily screen out the factors related to anxiety and its different levels. College students with different anxiety levels (mild anxiety, moderate anxiety, severe anxiety) were used as the dependent variable, and normal level was used as the reference, we carried out disordered multivariate logistic regression analysis (test of parallel lines was $\mathrm{P}<0.05)$ to analyze the risk factors affecting college students' different levels of anxiety. P-values $<0.05$ were considered to be statistically significant.

\section{Results}

\section{Sample Description}

There were 17,876 participants in this study. Overall, the mean age of the participants was $20.48 \pm 1.93$, median age was 20.00. Table 1 shows the basic information and different anxiety level of college students. Of the 17,876 college students, $81.8 \%$ of the students had no symptoms of anxiety, whereas the proportions of students with mild, moderate, and severe anxiety were $14.9 \%, 2.7 \%$, and $0.6 \%$, respectively, anxiety detection was $18.2 \%$.

\section{Factors Influencing College Students' Anxiety During the Epidemic Univariate Analysis}

Table 1 shows the relationship between the demographic variables of students and anxiety. The rate of male students was significantly higher than female students $(\mathrm{P}<0.001)$. The anxiety detection rate of college students with low satisfaction with the local control measures was higher $(\mathrm{P}<0.001)$. Moreover, education, character, profession, residence, concern about the outbreak, self-perceived risk of infection, impact of the outbreak, whether eager to back to school and feelings at home were of statistical significance.

\section{Multivariate Analysis}

Results of disordered multivariate logistic analysis of factors associated with anxiety during the COVID-19 crisis are presented in Table 2. We took the normal level as the reference and the significant factors from the univariate analysis were included in the multivariate analysis. The results indicated that male students $(1.267[1.153,1.393])$, (1.832[1.504, 2.231]), students whose self-perceived risk of infection were high $(1.777[1.320,2.394])$, (3.976[2.579, $6.129])$, students who were greatly affected by the outbreak $(2.452[2.155,2.790]),(3.410[2.464,4.719])$ and students who reluctant to leave home (1.442[1.232, 1.688]), (1.995[1.439, 2.767]) were risk factors for mild anxiety to moderate anxiety. Moreover, the detection rate of urban students' severe anxiety was significantly higher $(2.337[1.468,3.721])$.

\section{Discussion}

This survey indicated that $18.2 \%$ of college students suffered from anxiety at the peak of the COVID-19 epidemic in late February. Of these anxious students, $82.29 \%$ had mild anxiety, $14.66 \%$ and $3.05 \%$ of students had moderate to severe anxiety. A research among college students aged 18-24 years indicated that $83.1 \%$ had some anxiety about swine flu. ${ }^{28}$ Researches abroad noted that the prevalence of anxiety and high stress among Chinese students was much lower than in Foreign college students. ${ }^{22,29}$ Another study during the initial COVID-19 outbreak psychological states of 1210 general population showed that $28.8 \%$ reported moderate to severe anxiety symptoms. ${ }^{30}$ Besides, a survey among China's general population at the peak of the COVID-19 epidemic indicated that the prevalence of anxiety was $20.4 \% .^{31}$ The financial burden and family stress caused by massive quarantine was one of 
Table I College Students' Anxiety and Univariate Analysis

\begin{tabular}{|c|c|c|c|c|c|c|}
\hline Variables & Total & Normal & Mild Anxiety & Moderate Anxiety & Severe Anxiety & $P$ value \\
\hline Anxiety Level & $17,876(100)$ & $\mid 4,630(8 \mid .8)$ & $267 \mid(\mid 4.9)$ & $476(2.7)$ & $99(0.6)$ & \\
\hline Gender & & & & & & $<0.001$ \\
\hline Male & $5058(28.3)$ & $3935(77.8)$ & $883(7.5)$ & $202(4.0)$ & $38(0.8)$ & \\
\hline Female & $12,818(71.7)$ & $10,695(83.4)$ & $1788(13.9)$ & $274(2.1)$ & $61(0.5)$ & \\
\hline Nationality & & & & & & 0.080 \\
\hline Han & $15,850(88.7)$ & $12,982(81.9)$ & $2377(15.0)$ & $405(2.6)$ & $86(0.5)$ & \\
\hline Minority & $2026(11.3)$ & $1648(81.3)$ & $294(14.5)$ & $71(3.5)$ & $13(0.6)$ & \\
\hline Education & & & & & & $<0.001$ \\
\hline Two-and-three-years & $9230(51.6)$ & $7634(82.7)$ & $|32|(\mid 4.3)$ & $2 I I(2.3)$ & $64(0.7)$ & \\
\hline Undergraduate & $8185(45.8)$ & $6627(81.0)$ & $1276(15.6)$ & $25 I(3.1)$ & $31(0.4)$ & \\
\hline Master and above & $461(2.6)$ & $369(80.0)$ & $74(16.1)$ & $14(3.0)$ & $4(0.9)$ & \\
\hline Character & & & & & & 0.001 \\
\hline Partial outgoing & $3060(17.1)$ & $2555(83.5)$ & $422(13.8)$ & $69(2.3)$ & $14(0.5)$ & \\
\hline Partial introverted & $3882(21.7)$ & $3|5|(8 \mid .2)$ & $595(15.3)$ & $114(2.9)$ & $22(0.6)$ & \\
\hline Both & $8909(49.8)$ & $7334(82.3)$ & $1295(14.5)$ & $235(2.6)$ & $45(0.5)$ & \\
\hline Not clear & $2025(I 1.3)$ & $1590(78.5)$ & $359(17.7)$ & $58(2.9)$ & $18(0.9)$ & \\
\hline Profession & & & & & & 0.031 \\
\hline Medicine & $10,972(61.4)$ & $9016(82.2)$ & $1612(14.7)$ & $274(2.5)$ & $70(0.6)$ & \\
\hline Science and technology & $346 I(19.4)$ & $2829(81.7)$ & $532(15.4)$ & $93(2.7)$ & $7(0.2)$ & \\
\hline Liberal Arts & 1664(9.3) & 1328(79.8) & $269(16.2)$ & $55(3.3)$ & $12(0.7)$ & \\
\hline Management class and other majors & $1779(10.0)$ & $1457(81.9)$ & $258(14.5)$ & $54(3.0)$ & $10(0.6)$ & \\
\hline Residence & & & & & & 0.011 \\
\hline City & $4239(23.7)$ & $3462(81.7)$ & $636(15.0)$ & $102(2.4)$ & $39(0.9)$ & \\
\hline Town & $4524(25.3)$ & $3710(82.0)$ & $680(15.0)$ & $113(2.5)$ & $21(0.5)$ & \\
\hline Village & $9113(51.0)$ & $7458(81.8)$ & $1355(\mid 4.9)$ & $261(2.9)$ & $39(0.4)$ & \\
\hline $\begin{array}{l}\text { Satisfaction with local epidemic control } \\
\text { measure }\end{array}$ & & & & & & $<0.001$ \\
\hline High & $12,960(72.5)$ & $10,845(83.7)$ & $1766(13.6)$ & $294(2.3)$ & $55(0.4)$ & \\
\hline Moderate & $4632(25.9)$ & $3602(77.8)$ & $835(\mid 8.0)$ & $161(3.5)$ & $34(0.7)$ & \\
\hline Low & $284(1.6)$ & $183(64.4)$ & $70(24.6)$ & $2 \mathrm{I}(7.4)$ & $10(3.5)$ & \\
\hline Concern about the outbreak & & & & & & 0.006 \\
\hline High & $8195(45.8)$ & $6672(81.4)$ & $1221(14.9)$ & $247(3.0)$ & $55(0.7)$ & \\
\hline Moderate & $9259(51.8)$ & $7616(82.3)$ & $1391(15.0)$ & $212(2.3)$ & $40(0.4)$ & \\
\hline Low & $422(2.4)$ & $342(81.0)$ & $59(14.0)$ & $17(4.0)$ & $4(0.9)$ & \\
\hline Self-perceived risk of infection & & & & & & $<0.001$ \\
\hline High & $272(1.5)$ & $168(61.8)$ & $65(23.9)$ & $28(10.3)$ & II (4.0) & \\
\hline Moderate & $2398(\mid 3.4)$ & $1733(72.3)$ & $538(22.4)$ & $113(4.7)$ & $14(0.6)$ & \\
\hline Low & $15,206(85.1)$ & $12,729(83.7)$ & $2068(13.6)$ & $335(2.2)$ & $74(0.5)$ & \\
\hline Impact of the outbreak & & & & & & $<0.001$ \\
\hline High & $6492(36.3)$ & $4755(73.2)$ & $1364(2 \mid .0)$ & $292(4.5)$ & $81(1.2)$ & \\
\hline Moderate & $7294(40.8)$ & $6194(84.9)$ & $950(13.0)$ & $138(1.9)$ & $12(0.2)$ & \\
\hline Low & $4090(22.9)$ & $3681(90.0)$ & $357(8.7)$ & $46(1.1)$ & $6(0.1)$ & \\
\hline Eager to back to school & & & & & & $<0.001$ \\
\hline Yes & $7035(39.4)$ & $465 I(76.9)$ & $1110(18.3)$ & $243(4.0)$ & $48(0.8)$ & \\
\hline No & $6052(33.9)$ & $5956(84.7)$ & $905(12.9)$ & $143(2.0)$ & $31(0.4)$ & \\
\hline Not clear & $4789(26.8)$ & $4023(84.0)$ & $656(13.7)$ & $90(1.9)$ & $20(0.4)$ & \\
\hline
\end{tabular}

(Continued) 
Table I (Continued).

\begin{tabular}{|l|l|l|l|l|l|l|}
\hline Variables & Total & Normal & Mild Anxiety & Moderate Anxiety & Severe Anxiety & P value \\
\hline Feelings at home & & & & & & $<0.001$ \\
$\quad$ Stay enough & $7764(43.4)$ & $6063(78.1)$ & $1389(17.9)$ & $269(3.5)$ & $43(0.6)$ \\
$\quad$ Reluctant to leave & $1506(8.4)$ & $1189(79.0)$ & $246(16.3)$ & $55(3.7)$ & $16(1.1)$ & $40(0.5)$ \\
Other & $8606(48.1)$ & $7378(85.7)$ & $1036(12.0)$ & $152(1.8)$ & \\
\hline
\end{tabular}

Table 2 College Students' Level and Multivariate Analysis

\begin{tabular}{|c|c|c|c|c|c|c|}
\hline \multirow[t]{2}{*}{ Variables } & \multicolumn{2}{|l|}{ Mild Anxiety } & \multicolumn{2}{|l|}{ Moderate Anxiety } & \multicolumn{2}{|l|}{ Severe Anxiety } \\
\hline & OR $[95 \% \mathrm{CI}]$ & P value & OR $[95 \% \mathrm{Cl}]$ & P value & OR $[95 \% \mathrm{Cl}]$ & $P$ value \\
\hline \multicolumn{7}{|l|}{ Gender (ref: Female) } \\
\hline Male & $1.267[1.153,1.393]$ & $<0.001$ & $1.832[1.504,2.23 \mathrm{I}]$ & $<0.001$ & $1.574[1.025,2.4 \mid 7]$ & 0.038 \\
\hline \multicolumn{7}{|l|}{ Education (ref: Master and above) } \\
\hline Two-and three-years & $0.998[0.765,1.302]$ & 0.990 & $0.94 \mid[0.534, I .659]$ & 0.834 & I.I48[0.404, 3.258] & 0.796 \\
\hline Undergraduate & $\mathrm{I} .00 \mathrm{I}[0.767, \mathrm{I} .305]$ & 0.996 & $1.099[0.626,1.929]$ & 0.742 & $0.566[0.193,1.663]$ & 0.301 \\
\hline \multicolumn{7}{|l|}{ Character (ref: Not clear) } \\
\hline Partial outgoing & $0.709[0.604,0.832]$ & $<0.001$ & $0.722[0.500,1.041]$ & 0.081 & $0.548[0.264,1.136]$ & 0.106 \\
\hline Partial introverted & $0.815[0.702,0.946]$ & 0.007 & $0.944[0.678,1.315]$ & 0.734 & $0.770[0.403,1.470]$ & 0.428 \\
\hline Both & $0.753[0.658,0.86 I]$ & $<0.001$ & $0.85 \mid[0.628,1.152]$ & 0.296 & $0.667[0.374,1.190]$ & 0.170 \\
\hline \multicolumn{7}{|l|}{$\begin{array}{l}\text { Profession (ref: Management class and } \\
\text { other majors) }\end{array}$} \\
\hline Medicine & $1.016[0.875,1.182]$ & 0.831 & $0.890[0.650,1.218]$ & 0.466 & $0.972[0.487,1.94 I]$ & 0.936 \\
\hline Science and technology & $0.987[0.834,1.167]$ & 0.875 & $0.748[0.526,1.064]$ & 0.106 & $0.394[0.146,1.064]$ & 0.066 \\
\hline Liberal Arts & I.I96[0.988, I.449] & 0.067 & $1.247[0.84 \mathrm{I}, \mathrm{I} .849]$ & 0.271 & $1.643[0.689,3.9 \mid 8]$ & 0.263 \\
\hline \multicolumn{7}{|l|}{ Residence (ref: Rural) } \\
\hline Urban & $1.020[0.917,1.135]$ & 0.715 & $0.797[0.627,1.014]$ & 0.065 & $2.337[I .468,3.72 I]$ & $<0.001$ \\
\hline Town & $1.024[0.924,1.135]$ & 0.647 & $0.885[0.704,1.113]$ & 0.296 & $1.243[0.724,2.135]$ & 0.431 \\
\hline \multicolumn{7}{|l|}{$\begin{array}{l}\text { Satisfaction with local epidemic control } \\
\text { measure (ref: Low) }\end{array}$} \\
\hline High & $0.555[0.415,0.740]$ & $<0.001$ & $0.368[0.227,0.598]$ & $<0.001$ & $0.16 \mid[0.077,0.338]$ & $<0.001$ \\
\hline Moderate & $0.7 \mid 4[0.532,0.958]$ & 0.025 & $0.534[0.326,0.876]$ & 0.013 & $0.330[0.154,0.708]$ & 0.004 \\
\hline \multicolumn{7}{|l|}{ Concern about the outbreak (ref: Low) } \\
\hline High & $1.069[0.798,1.432]$ & 0.656 & $0.735[0.435,1.241]$ & 0.249 & $0.704[0.240,2.066]$ & 0.523 \\
\hline Moderate & I.II $7[0.837, \mathrm{I} .492]$ & 0.452 & $0.607[0.361,1.021]$ & 0.060 & $0.600[0.204,1.769]$ & 0.355 \\
\hline \multicolumn{7}{|l|}{ Self-perceived risk of infection (ref: Low) } \\
\hline High & $1.777[1.320,2.394]$ & $<0.001$ & $3.976[2.579,6.129]$ & $<0.001$ & $4.615[2.298,9.268]$ & $<0.001$ \\
\hline Moderate & $1.659[1.485,1.855]$ & $<0.001$ & $2.115[1.687,2.653]$ & $<0.001$ & $1.068[0.594,1.919]$ & 0.826 \\
\hline \multicolumn{7}{|l|}{ Impact of the outbreak (ref: Low) } \\
\hline High & $2.452[2.155,2.790]$ & $<0.001$ & $3.410[2.464,4.719]$ & $<0.001$ & $8.339[3.566,19.498]$ & $<0.001$ \\
\hline Moderate & $1.446[1.269,1.648]$ & $<0.001$ & $1.596[1.135,2.244]$ & 0.007 & $1.229[0.458,3.299]$ & 0.682 \\
\hline \multicolumn{7}{|l|}{ Eager to back to school (ref: Not clear) } \\
\hline Yes & $1.15 \mid[1.025,1.292]$ & 0.017 & $1.607[1.232,2.095]$ & $<0.001$ & $1.738[0.984,3.070]$ & 0.057 \\
\hline No & $0.936[0.836,1.047]$ & 0.245 & $1.022[0.776,1.345]$ & 0.879 & $0.969[0.539,1.742]$ & 0.915 \\
\hline \multicolumn{7}{|l|}{ Feelings at home (ref: Other) } \\
\hline Stay enough & $1.363[1.235,1.504]$ & $<0.001$ & $1.457[1.025,2.417]$ & 0.001 & $0.800[0.494,1.294]$ & 0.362 \\
\hline Reluctant to leave & $1.442[1.232, \mathrm{I} .688]$ & $<0.001$ & $1.995[1.439,2.767]$ & $<0.001$ & $1.876[1.012,3.477]$ & 0.046 \\
\hline
\end{tabular}


the general population's primary stressors related to anxiety, which would have worsened their mental health ${ }^{31-33}$ Therefore, it can be seen Chinese college students' anxiety was at a low level. Compared with the public, college students with high education have more knowledge and skill, which can alleviate psychological anxiety by actively learning knowledge related to the epidemic situation. ${ }^{34}$

The detection rate of anxiety among male students was significantly higher than female students, it was contrary to most studies, which found females suffered a greater psychological impact of the outbreak as well as higher levels of stress, anxiety, and depression. ${ }^{35}$ One possible reason for this result may be that the rate of introverted male students in our study was higher than female students (23.3\% VS 21.1\%). Studies have shown that introverts tend to be reluctant to give vent to their feelings, which results in a lot of negative emotional experiences and unable to be effectively released, leading to anxiety. ${ }^{36}$ Another probable reason was the rate of eager to back to school among male students was much higher than female students (40.2\% VS 31.3\%). Previous research has also shown that the self-esteem level of male college students was lower than that of female college students and the degree of irrational thinking of male college students was greater than that of female college students, so that they were more likely to be impulsive and anxious. ${ }^{37,38}$

The anxiety detection rate of college students with low satisfaction with the local control measures was higher. Strengthening prevention and control measures can not only block the spread of disease but also provide a sense of security, thus bringing potential psychological benefits. ${ }^{39}$ As the country and society paid more attention to the epidemic areas, the local control measures became more and more rigorous and comprehensive, which led to a positive effect on the initial psychological responses to the COVID-19 epidemic by giving respondents confidence and sense of control in prevention. ${ }^{35}$

Compared with college students in rural, the detection rate of urban students' severe anxiety was significantly higher, which was contrary to other findings. ${ }^{21}$ Although some studies believed that the urban provided citizens with better material security and sanitary conditions, ${ }^{40,41}$ according to National Health Commission of the P.R. China, $50.30 \%$ cities had been confirmed as of March 7, accounting for half of China's total. ${ }^{42}$ "Policy Brief on COVID-19 in an Urban World" released by the United Nations indicated that up to $90 \%$ of cases reported in cities. ${ }^{43}$ Such the situation may cause college students' potential psychological stress.

Compared with college students who was less affected by the epidemic, the anxiety detection rate of students who were greatly influenced were significantly high. This result is consistent with previous research. ${ }^{41,44,45}$ Kwok et al showed that Chinese universities were postponing classes or using distant/remote learning methods, which had a specific impact on the education and the growth of students. ${ }^{44}$ Tang et al showed that the Chinese government extended the national holidays to control the outbreak, which inevitably disrupted students' routine life $^{41}$ and resulted in anxiety.

Students with anxiety believed that they had high risk of novel coronavirus infection, especially some confirmed cases appeared around them, which was the same as that of Cao et al. ${ }^{21}$ A review showed that relatives or acquaintances being infected with COVID-19 was an independent risk factor in college students' anxiety about the epidemic, which might be related to the high contagiousness of the new coronavirus pneumonia. ${ }^{46}$

Our study has a large sample size, which included 17,876 students. The questionnaire reliability was 0.746 , the validity was 0.96 and study object had a high degree of education, they can express their basic emotions and perceptions, and the information was relatively complete and accurate. Therefore, the quality and results of the survey were relatively reliable and could be used as a historical reference. This study has several limitations. Given the time-sensitivity of the COVID-19 outbreak, we adopted the convenience sampling to collect the data, therefore our object cannot be seen as representative of the whole College students in China. Besides, although we stated in the online link that the subjects were college students, we also could not guarantee that all the people who filled in the questionnaire were college students because of the openness of online links. This study only analyzed the factors affecting anxiety, and did not further analyze the behaviors caused by college students' anxiety.

\section{Conclusion}

$18.2 \%$ of college students have experienced anxiety because of COVID-19 outbreak. Clear disposition, high satisfaction with control measures were protective factors for college students against anxiety. Male students, students whose self-perceived risk of infection were high, who were greatly affected by the outbreak and students who reluctant to leave home were risk factors for anxiety. 
Therefore, universities and colleges should set up relevant online psychological counseling platforms, pay attention to the publicity of epidemic prevention and control measures and online activities, and encourage college students to make vacation plans to reduce anxiety furthest. Future studies with behaviors and objective measures are encouraged to provide more information on this topic.

\section{Ethics Approval and Informed Consent}

Our research received the approval of the Shandong University of the Centre for Health Management and Policy Research (approval number is ECSHCMSDU20201106). Participations in the study were voluntary and an informed consent was provided at the beginning of the questionnaire link, with submission of responses implying the agreement to participate. All collected data were treated confidentially. This study complied with the Declaration of Helsinki.

\section{Consent for Publication}

The details of article can be published, and we have shown the article contents to be published.

\section{Acknowledgments}

We thank the L Lu, Y Li, Y Xia, A Jiao, F Hu, Z Hong and $\mathrm{Z}$ Gao who collected these data. The authors thank all the participants for their cooperation.

\section{Author Contributions}

All authors made a significant contribution to the work reported, whether that is in the conception, study design, execution, acquisition of data, analysis and interpretation, or in all these areas; took part in drafting, revising or critically reviewing the article; gave final approval of the version to be published; have agreed on the journal to which the article has been submitted; and agree to be accountable for all aspects of the work.

\section{Funding}

This research was funded by one grant from the National Natural Science Foundation of China, grant number 71974118.

\section{Disclosure}

The authors report no conflicts of interest in this work.

\section{References}

1. World Health Organization. WHO director-general's statement on IHR emergency committee on novel coronavirus (2019-nCoV). Available from: https://www.who.int/dg/speeches/detail/who-director -general-s-statement-on-ihr-emergency-committee-on-novelcoronavirus-(2019-ncov). Accessed January 30, 2020.

2. Stein MB. Editorial: COVID and anxiety and depression in 2020 Depress Anxiety. 2020;37(4):302. doi:10.1002/da.23014

3. Brand J, McKay D, Wheaton MG, Abramowitz JS. The relationship between obsessive compulsive beliefs and symptoms, anxiety and disgust sensitivity, and Swine Flu fears. J Obsessive Compuls Relat Disord. 2013;2(2):200-206. doi:10.1016/j.jocrd.2013.01.007.

4. Taylor S, Asmundson GJG. Treating Health Anxiety: A CognitiveBehavioral Approach. Guilford Press; 2004.

5. Taylor S, Abramowitz J, Mckay D. Hypochondriasis and HealthRelated Anxiety. 2012.

6. Zeng YL, Wang GF, Xie CX, Hu XY, Reinhardt JD. Prevalence and correlates of depression, anxiety and symptoms of stress in vocational college nursing students from Sichuan, China: a cross-sectional study. Psychol Health Med. 2019;24(7):798-811. doi:10.1080/13548506. 2019.1574358

7. Liu XQ, Ping SQ, Gao WJ. Changes in undergraduate students' psychological well-being as they experience university life. Int J Environ Res Public Health. 2019;16(16):14.

8. Pedrelli P, Nyer M, Yeung A, Zulauf C, Wilens T. College students: mental health problems and treatment considerations. Acad Psychiatry. 2015;39(5):503-511. doi:10.1007/s40596-014-0205-9

9. Li L. A study on the relationship between coping style and anxiety in college students. HuBei NongJiHua. 2019;(19):145.

10. Wang T, Chen R, Liu C, et al. Attention should be paid to venous thromboembolism prophylaxis in the management of COVID-19. Lancet Haematol. 2020;7(5):e362-e363. doi:10.1016/S2352-3026(20) 30109-5

11. Zhu N, Zhang D, Wang W, et al. A novel coronavirus from patients with pneumonia in China, 2019. $N$ Engl J Med. 2020;382 (8):727-733. doi:10.1056/NEJMoa2001017

12. Perlman S. Another decade, another coronavirus. $N$ Engl $J$ Med. 2020;382(8):760-762. doi:10.1056/NEJMe2001126

13. China, National Health Commission of the People's Republic of China. Guideline for psychological crisis intervention during 2019-nCoV; 2020. Available from: https://www.goven/xinwen/202001/27/content_5472433htm. Accessed March 20, 2020.

14. Chen QN, Liang MN, Li YM, et al. Mental health care for medical staff in China during the COVID-19 outbreak. Lancet Psychiatry. 2020;7(4):E15-E16. doi:10.1016/S2215-0366(20)30078-X

15. Yang Y, Li W, Zhang QG, Zhang L, Cheung T, Xiang YT. Mental health services for older adults in China during the COVID-19 outbreak. Lancet Psychiatry. 2020;7(4):E19-E19. doi:10.1016/S221 5-0366(20)30079-1

16. Zhang Y, Zhang HY, Ma XD, Di Q. Mental health problems during the COVID-19 pandemics and the mitigation effects of exercise: a longitudinal study of college students in China. Int J Environ Res Public Health. 2020;17(10):3722. doi:10.3390/ ijerph17103722

17. Savitsky B, Findling Y, Ereli A, Hendel T. Anxiety and coping strategies among nursing students during the covid-19 pandemic. Nurse Educ Pract. 2020;46:46. doi:10.1016/j.nepr.2020.102809

18. Sallam M, Dababseh D, Yaseen A, et al. Conspiracy beliefs are associated with lower knowledge and higher anxiety levels regarding COVID-19 among students at the University of Jordan. Int J Environ Res Public Health. 2020;17(14). doi:10.3390/ijerph17144915.

19. Mei SL, Yu JX, He BW, Li JY. Psychological investigation of university students in a university in Jilin province. Med Soc (Berkeley). 2011;24(5):84-86. 
20. Zihang Q, Ying H, Zi C, Shanshan J, Ting X, Dongsheng L. Effects of music therapy on anxiety of college students. China J Health Psychol. 2019;27(10):1539-1544.

21. Cao WJ, Fang ZW, Hou GQ, et al. The psychological impact of the COVID-19 epidemic on college students in China. Psychiatry Res. 2020;287:5. doi:10.1016/j.psychres.2020.112934

22. Rogowska AM, Kusnierz C, Bokszczanin A. Examining anxiety, life satisfaction, general health, stress and coping styles during COVID-19 pandemic in polish sample of university students. Psychol Res Behav Manag. 2020;13:797-811. doi:10.2147/PRBM. S266511

23. Li H, Jin D, Qiao F, Chen J, Gong J. Relationship between the self-rating anxiety scale score and the success rate of 64-slice computed tomography coronary angiography. Int J Psychiatry Med. 2016;51(1):47-55. doi:10.1177/0091217415621265

24. Zung WW, Magruder-Habib K, Velez R, Alling W. The comorbidity of anxiety and depression in general medical patients: a longitudinal study. J Clin Psychiatry. 1990;51:77-80.

25. Wang $\mathrm{C}$, Zhao H. The impact of COVID-19 on anxiety in Chinese university students. Front Psychol. 2020;11:1168. doi:10.3389/ fpsyg. 2020.01168

26. Ye R, Geng Q, Chen J, et al. Comparison of three scales to detect anxiety in general hospital outpatients: HADS, SAS and HAMA. Chin J Behav Med Brain Sci. 2013;22(3):271-273.

27. Tian Y, Wang Y, Li J, Wang M, Dang S. Evaluation of reliability and validity of self-rating anxiety scale and self-rating depression scale in patients with liver cirrhosis. J Pract Hepatol. 2019;22(01):105-108.

28. Kanadiya MK, Sallar AM. Preventive behaviors, beliefs, and anxieties in relation to the swine flu outbreak among college students aged 18-24 years. Z Gesundh Wiss. 2011;19(2):139-145. doi:10.10 07/s10389-010-0373-3

29. Rogowska A, Pavlova I, Kunierz C, Rogowska AM, Petrytsa P, Petrytsa P. Does physical activity matter for the mental health of university students during the COVID-19 pandemic? J Clin Med. 2020;9(11):3494. doi:10.3390/jcm9113494

30. Wang C, Pan R, Wan X, et al. A longitudinal study on the mental health of general population during the COVID-19 epidemic in China. Brain Behav Immun. 2020;87:40-48. doi:10.1016/j.bbi.2020. 04.028

31. Li J, Yang Z, Qiu H, et al. Anxiety and depression among general population in China at the peak of the COVID-19 epidemic. World Psychiatry. 2020;19(2):249-250. doi:10.1002/wps.20758

32. Lau JTF, Yang X, Tsui HY, Kim JH. Impacts of SARS on health-seeking behaviors in general population in Hong Kong. Prev Med. 2005;41(2):454-462. doi:10.1016/j.ypmed.2004.11.023

33. Lau JTF, Yang X, Tsui H, Kim JH. Monitoring community responses to the SARS epidemic in Hong Kong: from day 10 to day 62 . J Epidemiol Community Health. 2003;57(11):864-870. doi:10.1136/ jech.57.11.864
34. Zhang X, Ye T, Yao L, Song L, Wu Z. Psychological behavior of medical students during COVID-19 outbreak. J Trop Med. 2020;20 (5):567-580.

35. Wang C, Pan R, Wan X, et al. Immediate psychological responses and associated factors during the initial stage of the 2019 coronavirus disease (COVID-19) epidemic among the general population in China. Int J Environ Res Public Health. 2020;17(5):1729. doi:10.33 90/ijerph17051729

36. Feng F, Li M, Li R, Li B, Cao C. The mediated role of self-deficiency between alexithymia and psychological resilience among depressed college students. Chin J Behav Med Brain Sci. 2016;25(1):70-75.

37. Zhang XK, Tian LM. The relationship between self-esteem, depression and state anxiety of college students. China J Health Psychol. 2006;14(02):139-141.

38. Feng JX, Dai YL. Investigation on anxiety and causes of college students. J Northwest Univ. 2002;32(03):99-102.

39. Zhou SJ, Zhang LG, Wang LL, et al. Prevalence and socio-demographic correlates of psychological health problems in Chinese adolescents during the outbreak of COVID-19. Eur Child Adolesc Psychiatry. 2020;29(6):749-758. doi:10.1007/s00787-02001541-4

40. Shigemura J, Ursano RJ, Morganstein JC, Kurosawa M, Benedek DM. Public responses to the novel 2019 coronavirus (2019-nCoV) in Japan: mental health consequences and target populations. Psychiatry Clin Neurosci. 2020;74(4):281-282. doi:10. 1111/pcn. 12988

41. Tang B, Bragazzi NL, Li Q, Tang SY, Xiao YN, Wu JH. An updated estimation of the risk of transmission of the novel coronavirus (2019-nCov). Infect Dis Model. 2020;5:248-255. doi:10.1016/j. idm.2020.02.001

42. Zhang X. the epidemic is happening in cities does not mean we should take the path of urbanization. China Econ Trade Herald. 2020;05:70-71.

43. United Nations. Policy brief on COVID-19 in an urban world. Available from: https://unhabitat.org/un-secretary-general $\% \mathrm{E} 2 \% 80 \%$ 99s-policy-brief-on-covid-19-in-an-urban-world. Accessed July, 2020.

44. Kwok KO, Wong V, Wei VWI, Wong SYS, Tang JWT. Novel coronavirus (2019-nCoV) cases in Hong Kong and implications for further spread. $J$ Infect. 2020;80(6):689-690. doi:10.1016/j.jinf.20 20.02 .002

45. Solomou I, Constantinidou F. Prevalence and predictors of anxiety and depression symptoms during the COVID-19 pandemic and compliance with precautionary measures: age and sex matter. Int J Environ Res Public Health. 2020;17(14):4924. doi:10.3390/ ijerph17144924

46. Song Z, Xu Y, Bao L, et al. From SARS to MERS, thrusting coronaviruses into the spotlight. Viruses. 2019;11(1):59. doi:10.33 90/v11010059
Psychology Research and Behavior Management

\section{Publish your work in this journal}

Psychology Research and Behavior Management is an international, peer-reviewed, open access journal focusing on the science of psychology and its application in behavior management to develop improved outcomes in the clinical, educational, sports and business arenas. Specific topics covered in the journal include: Neuroscience, memory and decision making; Behavior modification and management; Clinical applications; Business and sports performance management; Socia and developmental studies; Animal studies. The manuscript management system is completely online and includes a very quick and fair peer-review system, which is all easy to use. Visit http://www. dovepress.com/testimonials.php to read real quotes from published authors. 